\title{
A retrospective observational study of anesthesia management during the flexible or rigid bronchoscopy in patients with central airway obstruction: Safety application of muscle relaxants and the traditional Low-frequency ventilation
}

Jing-Jin Li

The First Affiliated Hospital with Nanjing Medical University

Nan Li

The First Affiliate Hospital with Nanjing Medical University

\section{Wei-Jia Ma}

The First Affiliated Hospital with Nanjing Medical University

\section{Ming-Xue Bao}

The First Affiliated Hospital with Nanjing Medical University

\section{Zi-Yang Chen}

The First Affiliated Hospital with Nanjing Medical University

Zheng-Nian Ding ( $\nabla$ crystalni@qq.com )

The First Affiliate Hospital with Nanjing Medical University

\section{Research article}

Keywords: anesthesia management, bronchoscopy, central airway obstruction, muscle relaxants, traditional Low-frequency ventilation

Posted Date: December 2nd, 2020

DOl: https://doi.org/10.21203/rs.3.rs-57950/v2

License: (c) (i) This work is licensed under a Creative Commons Attribution 4.0 International License. Read Full License

Version of Record: A version of this preprint was published at BMC Anesthesiology on April 6th, 2021. See the published version at https://doi.org/10.1186/s12871-021-01321-w. 


\section{Abstract}

Background: Bronchoscopy treatments of central airway obstruction (CAO) under general anesthesia are high-risky procedures, and posing a giant challenge to the anesthesiologists. We summarized and analyzed our clinical experience in anesthesia management in patients with CAO undergoing flexible or rigid bronchoscopy, including the use of muscle relaxants, the traditional Low-frequency ventilation.

Methods: Clinical data of 375 patients with CAO who underwent urgent endoscopic treatments in general anesthesia from January 2016 to October 2019 were retrospectively reviewed. The use ratio of skeletal muscle relaxants, dose of skeletal muscle relaxants used, the incidence of perioperative adverse events, adequacy of ventilation and gas exchange, post-operative recovery between rigid bronchoscopy and flexible bronchoscopy therapy, and risk factors for postoperative ICU admission were evaluated.

Results: There was a high usage rate (96.5\%) of skeletal muscle relaxants in patients with CAO who underwent either flexible bronchoscopy or rigid bronchoscopy therapy and a higher dosage of skeletal muscle relaxants used in rigid bronchoscopy compared with flexible bronchoscopy therapy. This procedure had a low incidence of perioperative adverse events, with no significant difference between flexible and rigid bronchoscopy therapy. Sufficient ventilation was successfully established using the traditional Low-frequency ventilation both in flexible and rigid bronchoscopy group. There was a low mortality $(0.8 \%)$ during the post-operative recovery, and the higher grade of American Society of Anesthesiologists (ASA) and obvious dyspnea or orthopnea were the independent risk factors for postoperative ICU admission.

Conclusion: The muscle relaxants and low-frequency traditional ventilation can be safely used both in flexible and rigid bronchoscopy treatments in patients with CAO These results may provide strong clinical evidence for optimizing the anesthesia management of bronchoscopy for such patients.

\section{Background}

The quality of life of the patients is seriously impaired by severe CAO presented as severe dyspnea, stridor, or even respiratory failure. CAO is a potentially life-threatening condition, which has been treated in many ways ${ }^{[1,2]}$. For patients amenable to surgery, resection and reconstruction is the best therapeutic option. However, whenever surgery is not feasible, endoscopic therapies are needed ${ }^{[3,4]}$.

Nowadays, endoscopic treatment has been widely used as an effective method to treat CAO, palliating dyspnea in some cases of malignant obstruction and even be curative in some cases of benign tumor or inflammation ${ }^{[5-7]}$.Such procedures are mainly performed using rigid or flexible bronchoscope.

These interventions are high-risky procedures, posing a giant challenge to the anesthesiologists. How to establish adequate gas exchange to maintain the life of patients and allow good surgical access is what should be considered during anesthesia ${ }^{[6,8]}$. Furthermore, the choice of ventilation strategy and the use of skeletal muscle relaxants are still significant issues for anesthesiologists to consider. 
In this article, we summarized and analyzed our clinical experience in anesthesia management in patients with CAO undergoing flexible or rigid bronchoscopy in general anesthesia from January 2016 to October 2019 , including the use of muscle relaxants and the traditional Low-frequency ventilation, to estimate the safety of skeletal muscle relaxants application and the traditional Low-frequency ventilation.

\section{Methods}

\section{Study subjects}

A total of 427 patients with CAO underwent flexible bronchoscopy or rigid bronchoscopy in the First Affiliated Hospital with Nanjing Medical University from January 2016 to October 2019, of which the clinical data of 375 patients were retrospectively reviewed. Patients treated with various methods for controlling the airway were enrolled in this research, such as snare electrocoagulation, electrocautery, cryotherapy, argon plasma coagulation, balloon inflation and stent placement or removal(table1). Patients were excluded (1) if they were with intermedius space occupation or lower bronchus stenosis, foreign body, bronchopleural, bronchoesophageal , bronchomediastinal or tracheoesophageal fistula, biopsy by bronchoscopy; (2) if they had incomplete data or associated anomalies. This study has passed deliberation of the Clinical Ethics Committee of the First Affiliated Hospital with Nanjing Medical University (approval number: 2019-SR-505).

\section{Anesthesia management}

General anesthesia was conducted by anesthesiologists. All patients were monitored with Electrocardiograph (ECG), Pulse Oxygen Saturation $\left(\mathrm{SpO}_{2}\right)$, invasive arterial blood pressure (IABP), and given pre-oxygenation with 100\% oxygen, $8 \sim 10 \mathrm{~L} / \mathrm{min}$ for at least 3 minutes before anesthesia induction. General anesthesia was induced with etomidate or propofol, fentanyl or together with remifentanil, cisatracurium or rocuronium, with or without midazolam, and maintained with propofol and remifentanil. The depth of anesthesia was adjusted according to the intensity of surgical stimulation and hemodynamic indicators.

Laryngeal mask airway (LMA) or endotracheal intubation was used in flexible bronchoscopy. A side port of rigid bronchoscope was used for ventilation during the procedure, and LMA insertion or endotracheal intubation was performed immediately after the procedure for sustaining the ventilation. 8-10L/min pure oxygen was maintained during the whole operation. When the patient's $\mathrm{SpO}_{2}$ dropped below $90 \%$, the operation was stopped and the scope was removed to ventilate the patient. After a few minutes of ventilation, when the patient's $\mathrm{SpO}_{2}$ reached $99-100 \%$, then the operation continued. The patients were sent to the recovery room for resuscitation after operation, and muscle relaxant antagonists were given at appropriate time for patients who had no contraindications. Patients with the modified Aldrete score above 9 points were sent back to the general ward, while patients with the modified Aldrete score below 9 points or can't be extubated were sent to intensive care unit (ICU). 
On the basis of the anesthetic record of each patient, we analyzed the use rate of muscle relaxants, the dosage of muscle relaxants and analgesic, operation duration, recovery time, blood gas, End-tidal carbon dioxide $\left(\mathrm{EtCO}_{2}\right)$, the incidence of perioperative adverse events, postoperative outcomes and the risk factors for patients entering the ICU after surgery. The perioperative adverse events were failure of ventilation, bronchospasm, intraoperative cough, and hypoxemia, hypercapnia, reintubation after extubating. Bronchospasm was defined as wheezing or significantly increased airway pressure during mechanical ventilation, and hypoxemia was defined as oxygen saturation $<90 \%$.

\section{Statistical analysis}

SPSS version 23.0 program was used for statistical analysis, and results are expressed as mean \pm standard deviation $(X \pm S D)$. Chi-square test for counting data, $t$-test for measurement data, paired t test for paired groups date, Bivariate Correlation analysis for the correlation between two groups, and Binary Logistic regression analysis for risk factors of postoperative ICU admission. Statistical significance was set at $P<0.05$, and all tests were two-tailed.

\section{Results}

1. Clinical characteristics of included patients

Baseline clinical characteristics of included patients are shown in table 1. Of the 375 patients with CAO, 204 received flexible bronchoscopy treatments (flexible group) while the other 171 received rigid bronchoscopy treatments (rigid group). There were no significant differences in age, gender, BMI (body mass index), and ASA grades between the two groups. What's more, one or more airway procedures may be performed in the patient, such as placing a stent and then performing balloon dilation, ect.. Endobronchial stenting and Electrocoagulation (include snare electrocoagulation, electrocautery, highfrequency electrosurgical ablation, ect.) were the most utilized interventions during the flexible or rigid bronchoscopy, and there was no difference in airway procedures between the two groups (Table 1).

The malignant tumor is the main stenosis pathogen (68.8\%), and the main cause of CAO for performing flexible or rigid bronchoscopy is primary lung tumor (36.3\%). Other causal diseases are esophageal cancer, tracheal tumor, scarring, post-placement of stenting, thyroid tumor, lymphoma and tuberculosis (table 2). In all patients, the location of CAO in tracheal diagnosed by helical computed tomography (CT) scan or bronchoscopy was $66.7 \%$, while main bronchus (left or/and right main bronchus) stenosis was $33.3 \%$ (table 2). The etiology and location of CAO have no significant differences between the two groups.

2. The use of skeletal muscle relaxants

The use of skeletal muscle relaxants in patients with tracheal stenosis is a big challenge for anesthesiologists. In this research, skeletal muscle relaxants were used in $96.5 \%$ of the 375 included patients, in which $83.5 \%$ were cisatracurium, $12.0 \%$ rocuronium and $1.1 \%$ atracurium (Fig. $1 \mathrm{~A}$ ). The use 
rate of skeletal muscle relaxants was $96.5 \%$ in rigid bronchoscopy patients, and it was $96.6 \%$ in flexible bronchoscopy patients (Fig. 1BC).

The dosage of cisatracurium was higher in rigid bronchoscopy than in flexible group, but the duration of operation and awakening time had no difference between the two groups (Table 3). Although there was a high use rate of skeletal muscle relaxants in patients with CAO undergoing flexible or rigid bronchoscopy therapy, we found no patients with the failure of ventilation due to the use of skeletal muscle relaxants (table 3 ). In addition, no patients suffered bronchospasm or cough during the procedure, and two patients $(0.05 \%)$ were reintubated due to dyspnea after extubating (sent to ICU after adjusting the position of the bracket). There was no difference between the two groups in perioperative adverse events. The results may illustrate that the muscle relaxants can be safely used both in flexible and rigid bronchoscopy treatments in patients with CAO.

\section{Assessment of traditional Low-frequency ventilation}

Different from High or Low frequency jet ventilation, the traditional Low-frequency ventilation was used in all patients with $\mathrm{CAO}$. EtCO $\mathrm{C}_{2}$ and partial pressure of carbon dioxide in artery blood $\left(\mathrm{PaCO}_{2}\right)$ was investigated to evaluate the adequacy of ventilation and gas exchange (Fig.2). The level of $\mathrm{EtCO}_{2}$ in patients after either flexible bronchoscopy or rigid bronchoscopy both increased (Fig. 2A), but the increased extents were not very remarkable (35.76 \pm 7.71 VS $40.19 \pm 6.04,31.72 \pm 6.32$ VS $37.88 \pm 6.15$, respectively.) The same results were presented in $\mathrm{PaCO}_{2}$ (Fig. 2B). What's more, there was no correlation between the duration of operation and $\mathrm{EtCO}_{2}$ or $\mathrm{PaCO}_{2}$ after flexible bronchoscopy or rigid bronchoscopy therapy in patients with $\mathrm{CAO}$ (Fig.3). The results suggest the accumulation of $\mathrm{CO}_{2}$ may be not very severe in patients with CAO during the bronchoscopy therapy, and has no correlation with the duration of operation.

Of all patients, only 13 (8 in flexible, 5 in rigid) had the lowest $\mathrm{SpO}_{2}$ drop below 90\%, while 33 (15 in flexible, 18 in rigid) fluctuated between $90 \%-95 \%$ during the procedure(Table 4). $\mathrm{PaO}_{2}$ values were higher in the flexible group than in the rigid group during the therapy, yet both above $200 \mathrm{mmHg}(293.2 \pm 40.07$ vs $204.1 \pm 41.03 \mathrm{mmHg}$ ), and had no significant difference. The above results may show that the Lowfrequency traditional ventilation also can meet the adequacy of ventilation and gas exchange in patients with CAO undergoing bronchoscopy therapy.

\section{Post-operative recovery}

Following the procedure, 323 patients were sent back to the ward safely after waking up. 52 patients were transferred to ICU due to poor general condition, of which 3 patients died ( 2 due to hemoptysis and 1 due to acute myocardial infarction) in Day2 after the bronchoscopy therapy (Table 5).

The risk factors for patients entering ICU after surgery were conducted in this research. The correlation regression analysis indicated that higher ASA grade and obvious dyspnea or orthopnea were the independent risk factors for postoperative ICU admission (Table 6). 


\section{Discussion}

Central airway stenosis is known worldwide as a life-threatening condition with many causes ${ }^{[9-11]}$. In this study, we retrospectively reviewed 375 cases with CAO undergoing bronchoscopy with general anesthesia. The causes of CAO were primary tracheal tumors or lung cancer, esophageal cancer, scarring after tracheotomy, post-placement of stenting, mediastinal tumor, pulmonary metastatic tumor, and tracheomalacia etc.. As complications of these diseases, tracheal stenosis can be treated in many ways. Surgery may be the preferred approach, but not all patients are appropriate surgical candidates ${ }^{[4]}$. Therefore, bronchoscopy treatment remains the best tool for the safest management of airway obstructions, and provides prompt and durable palliation to patients ineligible for surgical treatment $[3,7$, $12,13]$

Both rigid and flexible bronchoscopes are now available for the interventional pulmonologists to perform this operation for advanced diagnostic and therapeutic purposes. There are some debates as which one is better than the other, and whether the use of muscle relaxants is safe and indispensable in this procedure ${ }^{[17-21]}$. In some articles, the authors are in favor of the non-use of muscle relaxants in rigid or flexible bronchoscopy for the safe factor, but in some operations, especially in advanced therapeutic and diagnostic procedures, undivided attention of the bronchoscopist and an immobile patient are required ${ }^{[19}$, 22]. A rigid bronchoscope can be placed in a nonparalyzed patient under deep sedation demanding high doses of analgesic and hypnotic agents, risking cardiovascular instability or residual drug effects harming pulmonary function after the operation. Trauma of the vocal cords and larynx leads to swelling and airway compromise, sometimes even accidental airway perforation could occur if poor insertion of the rigid bronchoscope is attempted even with adequate depth of anesthesia in a nonparalyzed patient, due to the significant response to tracheal manipulation. The use of topical anesthetics is recommended by the ACCP(American College of Chest Physicians ) for both basic and advanced bronchoscopy as it reduces the dose of sedative agents needed and effectively decreases cough ${ }^{[14]}$. Tracheal reflexes are blunted by incorporating a 'spray-as-you-go' technique of topical lidocaine spray via the working channel of the bronchoscope $\mathrm{e}^{[15]}$. The use of local anesthetics also can be observed in our research, but with the administration of muscle relaxants, which can provide good surgical conditions, the frequency and dose of local anesthetics were not so high. The use of muscle relaxants can facilitate the placement of rigid bronchoscope, ensure vocal cord adduction, and prevent life-threatening patient moving and coughing during the procedure, thus to provide the best operating conditions. Although SGA (supraglottic airway) insertion itself may not necessitate muscle paralysis, paralyzed vocal cords facilitates bronchoscopy in adduction position. Furthermore, muscle paralysis could attenuate the risk of patient's coughing and movements during the operation, as well as lower the chest wall resistance and reduce inspiratory pressures needed to achieve satisfactory tidal volumes ${ }^{[23-26]}$. At the beginning, we also did not dare to use muscle relaxants, but with the improvement of anesthesia equipment, visual technology, and anesthesia skills, we began to experiment with muscle relaxants. Approximately $96.5 \%$ patients among the 375 included patients were given skeletal muscle relaxants recorded in the anesthesia notes. 
Non-depolarizing muscle relaxants (Cis-atracurium, Atracurium, Rocuronium) instead of depolarizing muscle relaxants are preferred in our department, due to the moderate duration (close to 40 minutes) of the advanced procedure, Hofmann elimination mode and less histamine release, Cis-atracurium (in our department) has been the muscle relaxant of our choice. Short-acting depolarizing neuromuscular blocking drugs (e.g. succinylcholine) are suitable for insertion, but can lead to postoperative myalgia. The typically used non-depolarizing neuromuscular blocking agent of rocuronium has a longer half-life than the others and must be given with caution. The dosages of muscle relaxants and fentanyl used in rigid bronchoscopy are significantly higher than those used in the flexible bronchoscopy due to the higher degree of irritation.

Many patients with CAO already had hypoxia before surgery, and even $98.4 \%$ of the patients experienced symptoms of dyspnea ${ }^{[27]}$. Therefore, most of them inhaled oxygen when they entered the operating room for emergency bronchoscopy surgery. The $\mathrm{SpO}_{2}$ value of most patients was between $93 \%-100 \%$, which couldn't reflect the true hypoxia. In addition, hypoxemia and hypercapnia may commonly occur during bronchoscopic procedures. No patients were found could not be ventilated in our study under general anesthesia treated with muscle relaxants. We compared $\mathrm{ETCO}_{2}, \mathrm{PaCO}_{2}$ and $\mathrm{PaO}_{2}$ between the flexible and rigid bronchoscopy group. $\mathrm{PaCO}_{2}$ values were significantly higher than preoperative level in both groups, but there was no significant difference between the two groups. There was no statistical difference in recovery time and lowest pulse oxygen incidence between the two groups. In addition, there was no correlation between the operation time and $\mathrm{EtCO}_{2}$ or $\mathrm{PaCO}_{2}$ after flexible bronchoscopy or rigid bronchoscopy therapy in patients with $\mathrm{CAO}$. During the procedure, we noticed $\mathrm{SpO}_{2}$ decreased in nearly all patients, despite fraction of inspired oxygen $\left(\mathrm{FIO}_{2}\right)$ being kept at $100 \%$, but no patient suffered severe hypoxemia or hypercapnia. For patients undergoing some transient episodes of $\mathrm{SpO}_{2}$ lowering below $90 \%$, high fresh gas flows are often used to obtain adequate ventilation and compensate for the airway leakage. If it didn't work, we would remove the placed bronchoscope and then ventilate the patient for several minutes until $\mathrm{SpO}_{2}$ increased to above $95 \%$, then restart the procedure. The results show that the use of skeletal muscular relaxants may be safe in patients with CAO undergoing bronchoscopy therapy. In this study, we assume that the residual normal structure of the tracheal cartilage ring could maintain the airway and the continuously negative suction pressure produced by the operator acts like the way as passive lung ventilation. However, if the airway is highly skeptical of airway collapse, we will pay full attention to the patency of the airway to prevent the patient from being unable to be effectively intubated or ventilated.

In this process, the way of mechanical ventilation is also a key factor affecting gas exchange. A previous study has demonstrated no difference in arterial blood gas analysis values between jet ventilation and conventional ventilation during endobronchial laser surgery, yet jet ventilation may be associated with some complications including hypertension, hypoxemia, hypercapnia, and barotrauma ${ }^{[28]}$. In this study, the traditional Low-frequency ventilation was used in all patients with CAO. These results indicate that conventional ventilation mode using standard ventilator through the side port of the rigid bronchoscope can supply enough gas exchange at a relatively affordable cost. Since some cases have been excluded in 
our study due to the possible advantages of using HFJV in these cases, including bronchopleural, bronchoesophageal and bronchomediastinal fistulae, we still don't recommend the routine use of jet ventilation in the procedures described.

In this study, most of the patients with CAO who underwent bronchoscopy therapy were safely transferred to the ward (86.7\%), while the others were sent to ICU postoperatively due to their poor general condition. Three deaths ( 2 due to hemoptysis and 1 due to acute myocardial infarction) occurred during the procedures or within $48 \mathrm{~h}$ postoperatively, with a mortality rate of $0.8 \%$. The causes of these three deaths were not directly related to the procedures even though they occurred in the perioperative period. The rest of the patients $(99.2 \%)$ recovered without incidents in the recovery room in the immediate postoperative period.

Variables identified as increased complication rate predictors for therapeutic bronchoscopy (including both rigid and flexible) includes: emergent procedures, ASA physical status scores ${ }^{[28]}$. In this study, we revealed that the grade of ASA and obvious dyspnea or orthopnea were the independent risk factors for postoperative ICU admission. Therefore, ICU admission may be a safe option when an urgent bronchoscopy is carried out in patients with severe dyspnea, or with high ASA scores.

There are still some limitations in our study. Firstly, we did not have a blank control group to compare the procedures performed without muscle relaxants. Secondly, a lot of blood gas data were missing from the data during the operation. And thirdly, there was a lack of studies investigating the optimal dosages of muscle relaxants, we will design some prospective researches in the future.

\section{Conclusions}

The muscle relaxants and low-frequency traditional ventilation can be safely used both in flexible and rigid bronchoscopy treatment in patients with central airway obstruction. Given the rise in the interventional therapy, bronchoscopy treatments of CAO under general anesthesia may turn more frequent in the coming future, and this research may provide a safe anesthesia management option for its implementation.

\section{Abbreviations}

CAO:central airway obstruction; ECG:electrocardiograph; $\mathrm{SPO}_{2}$ :pulse Oxygen saturation; IABP: invasive arterial blood pressure; LMA: laryngeal mask airway; ICU: intensive care unit; EtCO2:end-tidal carbon dioxide; $\mathrm{BMI}$ :body mass index; ASA: American Society of Anesthesiologist; $\mathrm{PaO}_{2}$ :partial pressure of oxygen in artery; $\mathrm{PaCO}_{2}$ :partial pressure of carbon dioxide in artery; $\mathrm{FIO}_{2}$ : fraction inspired oxygen; SGA: supraglottic airway

\section{Declarations}




\section{Ethics approval and consent to participate}

Ethical approval was provided by the Ethics Committee of The First Affiliated Hospital with Nanjing Medical University, Nanjing, Jiangsu, China (approval number: 2019-SR-505 ) on December 25, 2019. The requirement for written informed consent was waived due to the retrospective nature of the study.

\section{Consent for publication}

Not applicable.

\section{Availability of data and materials}

The data sets used and/or analyzed during the current study available from the corresponding author on reasonable request.

\section{Competing interests}

The authors declare that they have no competing interests.

\section{Funding}

None.

\section{Authors' contributions}

ZND conceived the original idea and collaborated on the design of the study. JJL and NL collaborated on the design of the study, were in charge of collecting the data, analyzed and interpreted the patient data, and participated in writing the manuscript. ZYC was an active mentor throughout the study's development and substantively revised the final manuscript. WJM and MXB were in charge of collecting the data for the study. All authors read and approved the final manuscript.

\section{Acknowledgements}

Not applicable.

\section{Author details}

${ }^{1}$ Department of Anesthesiology and Perioperative Medicine, The First Affiliated Hospital with Nanjing Medical University, Nanjing, Jiangsu 210029, China;

\section{References}

[1]. Freitag, L., et al., A proposed classification system of central airway stenosis. European Respiratory Journal.2007;30(1): 7-12. 
[2]. Schieren, M., et al., New Approaches to Airway Management in Tracheal Resections-A Systematic Review and Meta-analysis. Journal of Cardiothoracic and Vascular Anesthesia. 2017;31(4): 1351-1358.

[3]. Petrella, F., et al., Operative rigid bronchoscopy: indications, basic techniques and results. Multimedia Manual of Cardio-Thoracic Surgery, 2014: p. mmu006-mmu006.

[4]. Fernando, H.C., J.T. Sherwood and W. Krimsky, Endoscopic Therapies and Stents for Benign Airway Disorders: Where Are We, and Where Are We Heading? The Annals of Thoracic Surgery.2010;89(6): S2183-S2187.

[5]. Oviatt, P.L., et al., Exercise Capacity, Lung Function, and Quality of Life After Interventional Bronchoscopy. Journal of Thoracic Oncology.2011;6(1): 38-42.

[6]. Sutterlin, R., et al., Influence of Tracheal Obstruction on the Efficacy of Superimposed High-frequency Jet Ventilation and Single-frequency Jet Ventilation. Anesthesiology. 2015; 123(4): 799-809.

[7]. Kim, H.J., et al., Clinical Experience of Rigid Bronchoscopy in Single Center. Tuberculosis and Respiratory Diseases.2012;72(6): 486.

[8]. Zhou, Y., et al., Anesthetic management of emergent critical tracheal stenosis. Journal of Zhejiang University SCIENCE B,.2007;8(7): 522-525.

[9]. Li, F., J. Liang and X. Li, Resection and Reconstruction of the Trachea for the Treatment of Upper Tracheal Stenosis: Tracheal Versus Non-Tracheal Intubation. J Coll Physicians Surg Pak. 2018;28(11): 879-881.

[10]. Farzanegan R, Feizabadi M, Ghorbani F, Movassaghi M, Vaziri E, Zangi M, Lajevardi S, Shadmehr MB. An overview of tracheal stenosis research trends and hot topics. Arch Iran Med. 2017; 598 - 607.

[11]. Zias N,Chroneou A,Tabba MK,Gonzalez AV , et al., Post tracheostomy and post intubation tracheal stenosis: report of 31 cases and review of the literature.BMC Pulmonary Medicine BioMed Central.2008;8:18.

[12]. Tsakiridis K,Darwiche K,Visouli AN, et al., Management of complex benign post-tracheostomy tracheal stenosis with bronchoscopic insertion of silicon tracheal stents, in patients with failed or contraindicated surgical reconstruction of trachea. J Thorac Dis.2012;4 (suppl 1):p.32-40.

[13]. Farahnak, M.R. and M.R. Moghimi, Rigid Bronchoscopy and Tracheostomy Compared to Repeated Dilatation of Tracheal Stenosis Prior to Tracheal Resection and Anastomosis; A Pilot Study. Polish Journal of Surgery. 2014;86(3):122-125.

[14]. de Lima, A., et al., Anesthesia for interventional pulmonology procedures: a review of advanced diagnostic and therapeutic bronchoscopy. Canadian Journal of Anesthesia/Journal canadien d'anesthésie.2018;65(7): 822-836. 
[15]. Pawlowski, J., Anesthetic considerations for interventional pulmonary procedures. Current Opinion in Anaesthesiology.2013;26(1): 6-12.

[16]. José, R.J., S. Shaefi and N. Navani, Anesthesia for bronchoscopy. Current Opinion in Anaesthesiology.2014;27(4): 453-457.

[17]. Agarwal, R., et al., Therapeutic rigid bronchoscopy at a tertiary care center in North India: Initial experience and systematic review of Indian literature. Lung India. 2014;31(1): 9.

[18]. Ayers ML, Beamis JF, Jr. Rigid bronchoscopy in the twenty-first century. Clin Chest Med. 2001;22: 355-64.

[19]. Ernst A, Feller-Kopman D, Becker HD, Mehta AC. Central airway obstruction. Am J Respir Crit Care Med. 2004;169: 1278-97

[20]. Panchabhai, T.S. and A.C. Mehta, Historical Perspectives of Bronchoscopy. Connecting the Dots. Annals of the American Thoracic Society. 2015;12(5): 631-641.

[21]. Haas, A.R., A. Vachani and D.H. Sterman, Advances in Diagnostic Bronchoscopy. American Journal of Respiratory and Critical Care Medicine.2010;182(5): 589-597.

[22]. Semaan, R. and L. Yarmus, Rigid bronchoscopy and silicone stents in the management of central airway obstruction. Journal of thoracic disease.2015; 7(Suppl 4): S352-S362.

[23]. Galway, U., et al., Anesthetic considerations for bronchoscopic procedures: a narrative review based on the Cleveland Clinic experience. Journal of Thoracic Disease.2019; 11(7): p. 3156-3170.

[24]. José, R.J., S. Shaefi and N. Navani, Anesthesia for bronchoscopy. Current Opinion in Anaesthesiology. 2014;27(4): 453-457.

[25]. Norimasa Matsuda, Satoshi Matsumoto, et al.,Taku Nishimura,Perioperative management for placement of tracheobronchial stents. Journal of Anesthesia.2006;20: 113-117

[26]. Goudra, B.G., et al., Anesthesia for Advanced Bronchoscopic Procedures: State-of-the-Art Review. Lung. 2015;193(4): 453-465.

[27]. Khan, A., et al., Rigid bronchoscopic interventions for central airway obstruction - An observational study. Lung India.2020;37(2): 114.

[28]. de Lima, A., et al., Anesthesia for interventional pulmonology procedures: a review of advanced diagnostic and therapeutic bronchoscopy. Canadian Journal of Anesthesia/Journal canadien d'anesthésie.2018;65(7): 822-836.

\section{Tables}


Table 1. Patient baseline characteristics. BMI, Body Mass Index; ASA, American Society of Anesthesiologist.

\begin{tabular}{|c|c|c|c|c|}
\hline \multirow[b]{2}{*}{ Characteristics } & \multicolumn{3}{|c|}{$\mathrm{N}(\%)$} & \multirow[b]{2}{*}{$P$ value } \\
\hline & $\begin{array}{c}\text { Flexible } \\
\text { bronchoscope } \\
(204)\end{array}$ & $\begin{array}{c}\text { Rigid } \\
\text { bronchoscope } \\
(171)\end{array}$ & $\begin{array}{c}\text { Total } \\
(375)\end{array}$ & \\
\hline Age, median(range), year & $63(16 \sim 89)$ & $62(12 \sim 87)$ & $62(12 \sim 89)$ & 0.70 \\
\hline Gender (M: F) & $115: 89$ & $106: 65$ & 221:154 & 0.271 \\
\hline BMI(\%) & $22.5 \pm 3.4$ & $21.8 \pm 3.5$ & $22.2 \pm 3.4$ & 0.127 \\
\hline \multicolumn{5}{|l|}{ ASA } \\
\hline $\mathrm{II} \sim \mathrm{III}$ & $156(76.5 \%)$ & $127(74.3 \%)$ & $286(75.5 \%)$ & \\
\hline IV & $44(21.6 \%)$ & $39(22.8 \%)$ & $84(22.1 \%)$ & \\
\hline V & $4(2.0 \%)$ & $5(2.9 \%)$ & $9(2.4 \%)$ & 0.915 \\
\hline \multicolumn{5}{|l|}{ Airway procedures } \\
\hline Endobronchial stenting & $91(44.6 \%)$ & $87(50.9 \%)$ & $178(47.5 \%)$ & 0.226 \\
\hline Balloon dilatation & $29(14.2 \%)$ & $25(14.6 \%)$ & $54(14.4 \%)$ & 0.912 \\
\hline Argon plasma coagulation & $14(6.9 \%)$ & $10(5.8 \%)$ & $24(6.4 \%)$ & 0.689 \\
\hline Cryoablation & $12(5.9 \%)$ & $8(4.73 .5 \%)$ & $20(5.3 \%)$ & 0.605 \\
\hline Endobronchial laser & $7(3.4 \%)$ & $3(1.8 \%)$ & $10(2.7 \%)$ & 0.315 \\
\hline Electrocoagulation & $89(43.6 \%)$ & $78(45.6 \%)$ & $167(44.5 \%)$ & 0.700 \\
\hline Stent removal & $3(1.5 \%)$ & $4(2.3 \%)$ & $7(1.9 \%)$ & 0.536 \\
\hline
\end{tabular}

Table 2. Etiology and location of patients with CAO undergoing flexible bronchoscopy or rigid bronchoscopy.

\begin{tabular}{|c|c|c|c|c|}
\hline & \multicolumn{3}{|c|}{$N(\%)$} & \multirow[b]{2}{*}{$P$ value } \\
\hline & $\begin{array}{c}\text { Flexible } \\
\text { bronchoscopy }\end{array}$ & $\begin{array}{c}\text { Rigid } \\
\text { bronchoscopy }\end{array}$ & Total & \\
\hline \multicolumn{5}{|l|}{ Etiology of CAO } \\
\hline Lung tumor & $79(38.7 \%)$ & $57(33.3 \%)$ & $136(36.3 \%)$ & \\
\hline Esophageal cancer & $45(22.1 \%)$ & $42(24.6 \%)$ & $87(23.2 \%)$ & \\
\hline Tracheal tumor & $39(19.2 \%)$ & $26(15.2 \%)$ & $65(17.4 \%)$ & \\
\hline Scarring & $25(12.3 \%)$ & $23(13.5 \%)$ & $48(12.8 \%)$ & \\
\hline Post-placement of stenting & $9(4.4 \%)$ & $13(7.9 \%)$ & $22(5.6 \%)$ & \\
\hline Thyroid tumor & $4(2.0 \%)$ & $4(2.3 \%)$ & $8(2.1 \%)$ & \\
\hline Lymphoma & $1(0.5 \%)$ & $3(1.8 \%)$ & $4(1.1 \%)$ & \\
\hline Tuberculosis & $2(1.0 \%)$ & $3(1.8 \%)$ & $5(1.3 \%)$ & 0.418 \\
\hline \multicolumn{5}{|l|}{ Benign/Malignant } \\
\hline Benign & $72(35.3 \%)$ & $45(26.3 \%)$ & $117(31.2 \%)$ & \\
\hline Malignant & $132(64.7 \%)$ & $126(73.7 \%)$ & $258(68.8 \%)$ & 0.062 \\
\hline \multicolumn{5}{|l|}{ Location of CAO } \\
\hline Tracheal & $130(63.7 \%)$ & $120(73.2 \%)$ & $250(66.7 \%)$ & \\
\hline Right or left main bronchus & $74(36.3 \%)$ & $51(29.8 \%)$ & $125(33.3 \%)$ & 0.187 \\
\hline
\end{tabular}

Table3. The comparison of skeletal muscular relaxants and perioperative adverse events between flexible bronchoscopy and rigid bronchoscopy therapy in patients with CAO. 


\begin{tabular}{|c|c|c|c|c|}
\hline \multirow{2}{*}{ events } & \multicolumn{2}{|c|}{$N(\%)$} & \multirow[b]{2}{*}{ total } & \multirow[b]{2}{*}{$\begin{array}{c}P \\
\text { value }\end{array}$} \\
\hline & $\begin{array}{c}\text { Flexible } \\
\text { bronchoscope }\end{array}$ & $\begin{array}{c}\text { Rigid } \\
\text { bronchoscope }\end{array}$ & & \\
\hline Cisatracurinm (mg) & $10.8 \pm 3.8(n=177)$ & $11.9 \pm 3.6 \quad(n=136)$ & $11.3 \pm 3.8$ & 0.008 \\
\hline Procedure duration(min) & $41.4 \pm 32.5$ & $41.5 \pm 29.9$ & $41.1 \pm 31.3$ & 0.961 \\
\hline Awakening duration (min) & $25.3 \pm 21.0(n=179)$ & $25.8 \pm 17.3(n=144)$ & $25.6 \pm 19.4$ & 0.815 \\
\hline \multicolumn{5}{|l|}{ Perioperative adverse events } \\
\hline Failure of ventilation & 0 & 0 & 0 & 1.000 \\
\hline Bronchospasm & 0 & 0 & 0 & 1.000 \\
\hline Intraoperative cough & 0 & 0 & 0 & 1.000 \\
\hline Hypoxemia & $8(3.9 \%)$ & $5(2.9 \%)$ & $13(3.5 \%)$ & 0.779 \\
\hline Reintubation after extubation & $2(0.98 \%)$ & 0 & & 0.503 \\
\hline
\end{tabular}

Table 4. Patients with lowest $\mathrm{SPO}_{2}<95 \%$ and oxygen pressure $\left(\mathrm{PO}_{2}\right)$ during the therapy $\left(\mathrm{PO}_{2}: \mathrm{n}=18\right.$ in flexible group and $\mathrm{n}=17 \mathrm{in}$ rigid group recorded in the anesthesia note).

\begin{tabular}{ccccc}
\hline \multirow{2}{*}{ The lowest SPO2 } & \multicolumn{3}{c}{$\mathrm{N}(\%)$} & \multirow{2}{*}{ P value } \\
\cline { 2 - 4 } & $\begin{array}{c}\text { Flexible } \\
\text { bronchoscope }\end{array}$ & $\begin{array}{c}\text { Rigid } \\
\text { bronchoscope }\end{array}$ & total & \\
\hline$<90 \%$ & $8(3.9 \%)$ & $5(2.9 \%)$ & $13(3.5 \%)$ & \\
$90 \% \sim 95 \%$ & $15(7.3 \%)$ & $18(10.5 \%)$ & $33(8.8 \%)$ & 0.475 \\
PO2 $(\mathrm{mmHg})$ & $293.2 \pm 174.66$ & $204.1 \pm 158.90$ & $253.9 \pm 171.37$ & 0.134 \\
\hline
\end{tabular}

Table 5. Post-operative recovery.

\begin{tabular}{lcccc}
\hline \multirow{2}{*}{ outcome } & \multicolumn{3}{c}{$\mathrm{N}(\%)$} & \multirow{2}{*}{ P value } \\
\cline { 2 - 4 } & $\begin{array}{c}\text { Flexible } \\
\text { bronchoscope }\end{array}$ & $\begin{array}{c}\text { Rigid } \\
\text { bronchoscope }\end{array}$ & total & \\
\hline Ward & 177 & 146 & $323(86.7 \%)$ & 0.765 \\
ICU & 27 & 25 & $52(13.3 \%)$ & 0.594 \\
Death & 1 & 2 & $3(0.8 \%)$ & \\
\hline
\end{tabular}

Table 6. Logistic regression analysis for risk factors for postoperative ICU admission. 


\begin{tabular}{llllll}
\hline Risk factors & COR $(\beta$-value $)$ & SE & Wald x2 & OR $(95 \% \mathrm{Cl})$ & P value \\
\hline Age & 0.016 & 0.015 & 1.207 & $1.106(0.998 \sim 1.046)$ & 0.272 \\
Gender & -0.292 & 0.336 & 0.755 & $0.746(0.386 \sim 1.443)$ & 0.385 \\
ASA & -0.757 & 0.257 & 8.665 & $0.469(0.283 \sim 0.777)$ & 0.003 \\
Hypertension & 0.207 & 0.398 & 0.272 & $1.230(0.564 \sim 2.684)$ & 0.602 \\
Diabetes & 0.227 & 0.559 & 0.164 & $1.254(0.419 \sim 3.752)$ & 0.685 \\
Abnormal ECG & 0.081 & 0.403 & 0.040 & $1.084(0.492 \sim 2.386)$ & 0.841 \\
Coronary heart disease & -0.135 & 0.627 & 0.046 & $0.874(0.256 \sim 2.987)$ & 0.830 \\
Dyspnea or orthopnea & 1.057 & 0.400 & 6.995 & $2.878(1.315 \sim 6.298)$ & 0.008 \\
Lung infection & 0.648 & 0.346 & 3.514 & $1.911(0.971 \sim 3.763)$ & 0.061 \\
Respiratory failure before procedure & 0.545 & 0.423 & 1.664 & $1.725(0.753 \sim 3.952)$ & 0.197 \\
Cerebrovascular disease & 0.080 & 0.543 & 0.022 & $1.083(0.374 \sim 3.139)$ & 0.883 \\
Benign/Malignant & -0.275 & 0.430 & 0.411 & $0.759(0.327 \sim 1.762)$ & 0.552 \\
Location of stenosis & 0.494 & 0.413 & 1.431 & $1.640(0.729 \sim 3.686)$ & 0.232 \\
Flexible/rigid bronchoscope & -0.120 & 0.336 & 0.127 & $0.887(0.459 \sim 1.715)$ & 0.722 \\
Constant & -0.924 & 3.220 & 0.082 & 0.397 & 0.774 \\
\hline
\end{tabular}

\section{Figures}

A

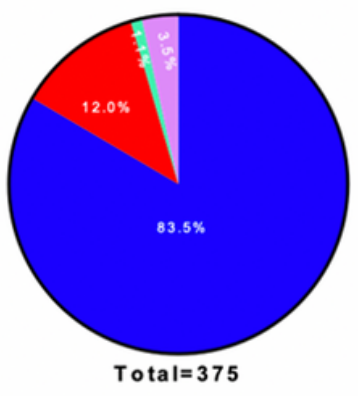

Flexible and rigid bronchoscope
B

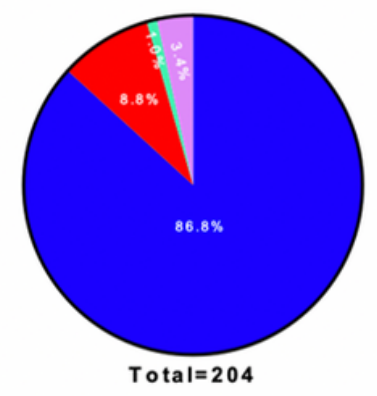

Flexible bronchoscope
C

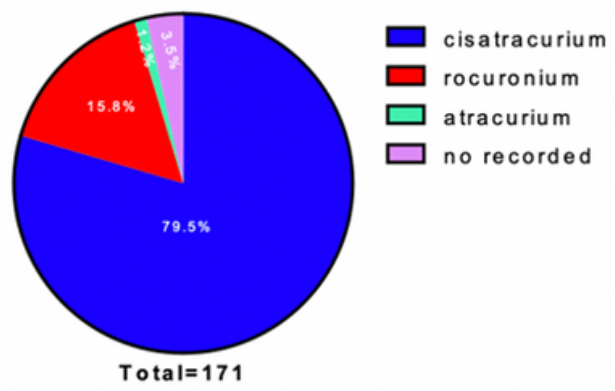

Rigid bronchoscope

\section{Figure 1}

Utilization rate of skeletal muscular relaxants in patients with CAO undergoing flexible bronchoscopy or rigid bronchoscopy. 
A

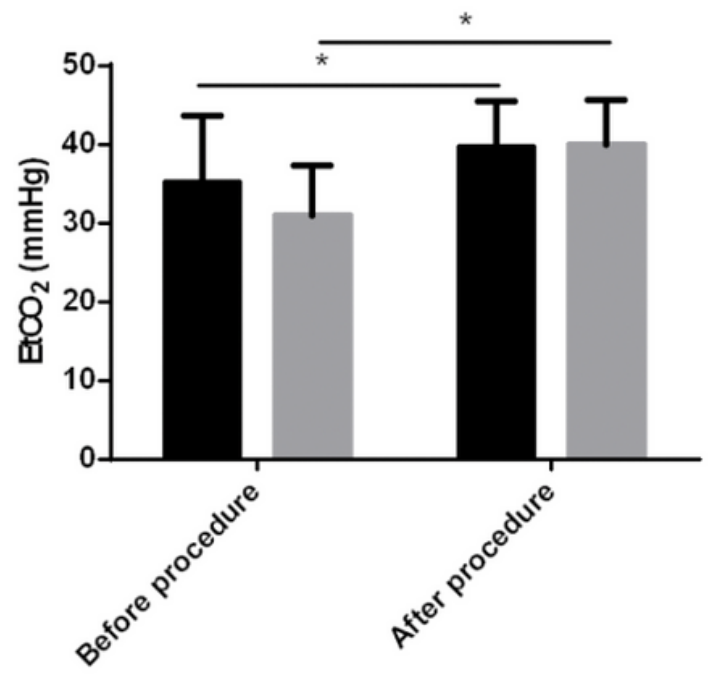

B

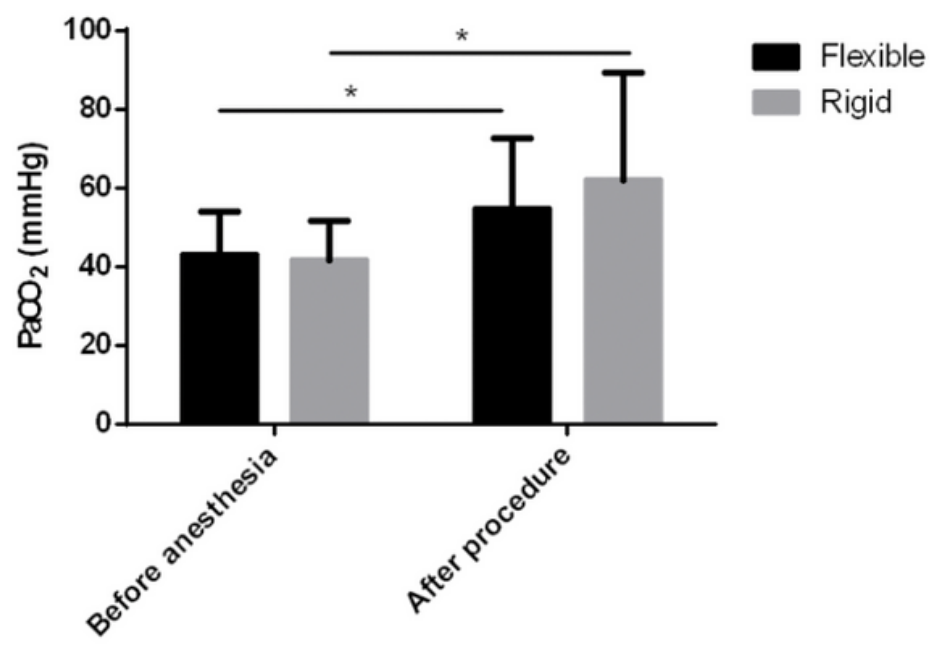

\section{Figure 2}

Change in $\mathrm{EtCO} 2$ and $\mathrm{PaCO} 2$ before and after therapy in patients with $\mathrm{CAO}$. A, Change in EtCO2 before and after procedure ( $n=100$ in flexible group and $n=57$ in rigid group recorded in the anesthesia note). $B$, Change in $\mathrm{PaCO} 2$ before anesthesia and after procedure $(\mathrm{n}=18$ in flexible group and $\mathrm{n}=17$ in rigid group recorded in the anesthesia note). Paired $t$ test used in these data, ${ }^{*} p<0.05$, Flexible: flexible bronchoscopy treatment; Rigid: rigid bronchoscopy treatment. 
A

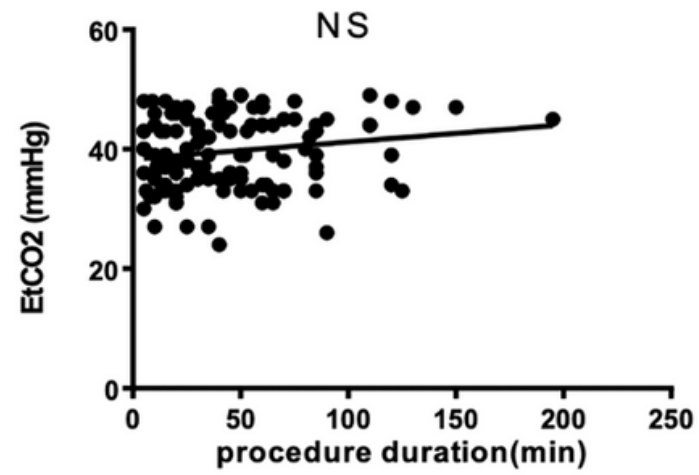

flexible

C

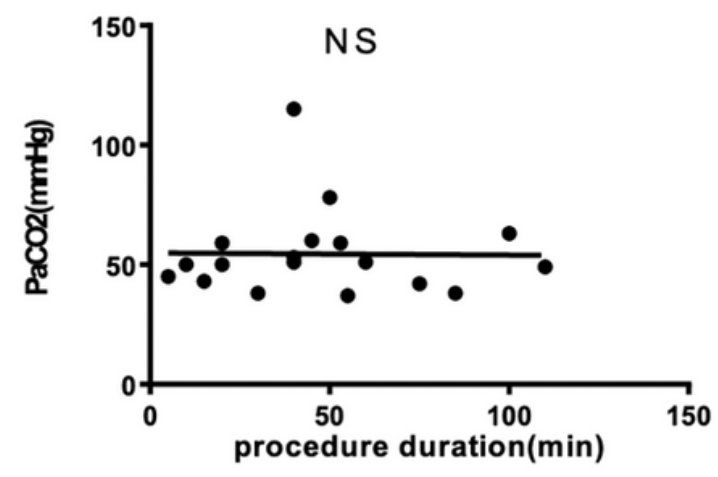

flexible
B

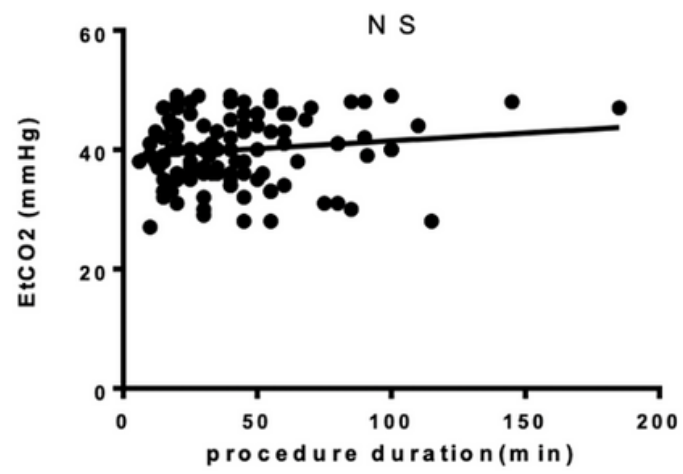

rig id

D

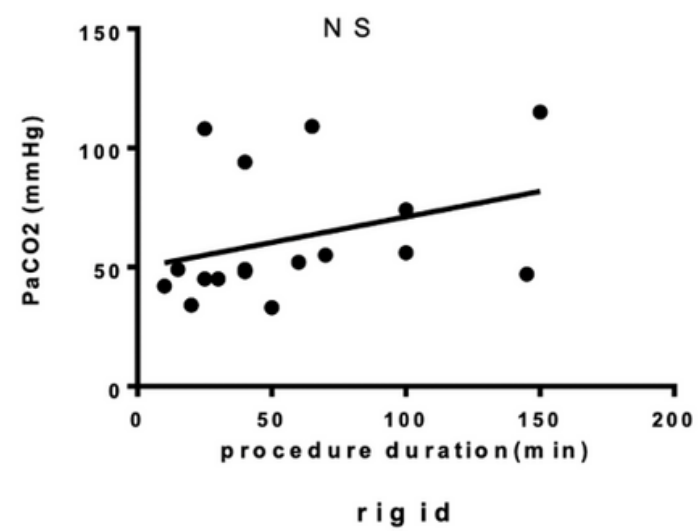

Figure 3

The Correlation between the length of operation time and EtCO2 or PaCO2 after flexible bronchoscopy or rigid bronchoscopy therapy in patients with $\mathrm{CAO}$. A,B,The correlation between the length of operation time and EtCO2 after flexible bronchoscopy and rigid bronchoscopy therapy $(n=133$ in flexible group and $\mathrm{n}=121$ in rigid group recorded in the anesthesia note). C,D, The correlation between the length of operation time and $\mathrm{PaCO} 2$ after flexible bronchoscopy and rigid bronchoscopy therapy $(\mathrm{n}=18$ in flexible group and $n=16$ in rigid group recorded in the anesthesia note). 